\title{
Transmission Electron Microscopy Observation of Twin Variant Selection in Austenitic Twinning-Induced Plasticity Steel
}

\author{
Jung-Hoon Han, Juhyun Oh, Sangmoon Yoon, Yanghoo Kim, Heung Nam Han, Miyoung Kim* \\ Department of Materials Science and Engineering and Research Institute of Advanced Materials, \\ Seoul National University, Seoul 08826, Korea
}

\author{
*Correspondence to: \\ Kim M, \\ Tel: +82-2-880-9239 \\ Fax: +82-2-884-1413 \\ E-mail: mkim@snu.ac.kr \\ Received December 5, 2016 \\ Revised December 14, 2016 \\ Accepted December 14, 2016
}

\begin{abstract}
Twinning-induced plasticity (TWIP) steels with the austenite structure containing high manganese exhibit both good strength and excellent formability. Such properties originate from crystallographic slip and mechanical twins produced when the austenite structure is under mechanical stress. There are 12 twin systems, referred to as twin variants, when slip is induced. These twin systems include twin planes and twin directions and play an important role in determining strength and ductility of the material by strongly influencing texture formation of the austenite structure. In the present study, twins produced in a high-Mn TWIP steel as a result of uniaxial tension were observed using a transmission electron microscope; a comparative analysis was performed through interaction energy calculations. Electron diffraction was used to determine the twin system with respect to the uniaxial tension direction in each grain. Both the Schmid factors and interacting energies required for the generation of twins were calculated and subsequently compared with experimental results. This approach demonstrated the possibility of predicting the deformation behavior of the material.
\end{abstract}

Key Words: Twinning-induced plasticity steel, Twin variants, Transmission electron microscopy, Interaction energy

\section{INTRODUCTION}

Many industrial applications involving both high structural performance and good component formability require materials with high ductility and strength. Because these two properties are generally antagonistic for most materials, improving both simultaneously is difficult. Twinning-induced plasticity (TWIP) steels, which combine high strength with better formability than conventional steels, has attracted much interest over the past 10 years because of their perceived ability to simultaneously possess these two characteristics (Allain et al., 2004; Hua et al., 2006; Vercammen et al., 2004). The high performance of TWIP steels is attributed to the appearance of crystallographic slip and to mechanical twinning under an external force.

During mechanical twinning, the parent austenite usually has an orientation relationship with the newly formed twin; a crystallographic texture of the austenite thereby strongly influences the texture development in the inherited twin. For a given orientation relationship, the inherited twin has several equivalent orientations, which are called variants and are listed in Table 1. In the idealized case, all variants can appear in an austenite grain with an equal probability during twining. Under an applied stress, however, some variants have greater relative probability to be selected. This phenomenon, which is called variant selection, is known to strongly affect the texture development in the inherited twin.

In present study, the variant selection in mechanical twinning of austenite is investigated with respect to the interaction between applied uniaxial stress and lattice deformation of the twinning. The orientations of parent austenite and newly formed twins under tensile deformation are measured using transmission electron microscopy (TEM). For an individual austenite grain, the orientations of 12 variants are evaluated

(a) This is an open-access article distributed under the terms of the Creative Commons Attribution Non-Commercial License (http://creativecommons.org/licenses/by-nc/4.0) which permits unrestricted noncommercial use, distribution, and reproduction in any medium, provided the original work is properly cited.

Copyrights () 2016 by Korean Society of Microscopy 
Table 1. The twelve mechanical twinning systems in austenite

\begin{tabular}{rlllrr}
\hline No. & \multicolumn{5}{c}{ Twin variant } \\
\hline 1 & $(1$ & 1 & $1)[1$ & 1 & $-2]$ \\
2 & $(1$ & 1 & $1)[1$ & -2 & $1]$ \\
3 & $(1$ & 1 & $1)[-2$ & 1 & $1]$ \\
4 & $(1$ & -1 & $-1)[1$ & -1 & $2]$ \\
5 & $(1$ & -1 & $-1)[1$ & 2 & $-1]$ \\
6 & $(1$ & -1 & $-1)[-2$ & -1 & $-1]$ \\
7 & $(-1$ & 1 & $-1)[-1$ & 1 & $2]$ \\
8 & $(-1$ & 1 & $-1)[-1$ & -2 & $-1]$ \\
9 & $(-1$ & 1 & $-1)[2$ & 1 & $-1]$ \\
10 & $(-1$ & -1 & $1)[-1$ & -1 & $-2]$ \\
11 & $(-1$ & -1 & $1)[-1$ & 2 & $1]$ \\
12 & $(-1$ & -1 & $1)[2$ & -1 & $1]$ \\
\hline
\end{tabular}

and compared with the observed twin orientation. The interaction energy between externally applied stress and lattice deformation is calculated for each of the 12 variants, and the probability of variant selection is assessed. The assessed probability is compared with the experimental results.

\section{Interaction Energies of the Twin Systems and the Schmid Factor}

The strength of TWIP steels can exceed $800 \mathrm{MPa}$, and their elongation can be as high as $70 \%$ (Frommeyer et al., 2003); TWIP steels can also undergo structural changes via mechanical twins under external stress. Such behavior is attributable to the low stacking fault energy (SFE) of the austenite structure. The SFE varies according to composition and temperature of the material. Mechanical twinning occurs more easily with a smaller SFE (Hull \& Bacon, 2001). However, the austenite structure is transformed into the $\in$-martensite structure when the SFE is too low; values in the range $16<\mathrm{SFE}<25 \mathrm{~mJ} / \mathrm{m}^{2}$ are known to give rise to a stable condition (Frommeyer et al., 2003; Idrissi et al., 2009). In general, TWIP steels contain $3 \mathrm{wt} \% \mathrm{Si}, 3 \mathrm{wt} \% \mathrm{Al}$, and greater than $15 \mathrm{wt} \%$ of $\mathrm{Mn}$, where $\mathrm{Mn}$, as a stabilizing element for the austenite structure, also plays a role in lowering the SFE until the composition reaches to an optimum value.

Interaction energy is frequently used to explain deformation phenomena in materials. Interaction energy is calculated as the sum of the product of the stress tensor $\left(\sigma_{i j}^{s}\right)$ and the strain tensor $\left(\varepsilon_{i j}^{s}\right), U^{i}=\sigma_{i j}^{s} \varepsilon_{i j}^{s}$ and represents the energy required for the deformation when an external force is applied to the material. In this study, our objective was to determine the most easily produced twin system that could be generated in each grain through the calculation of all interaction energies for 12 twin systems under an applied stress (Lee et al., 2005). When uniaxial stress is applied to the crystal, the well-known Schmid factor value for each twin system is closely related to the interaction energy (Ahn et al., 2014).

In the present study, we confirmed that interaction energies

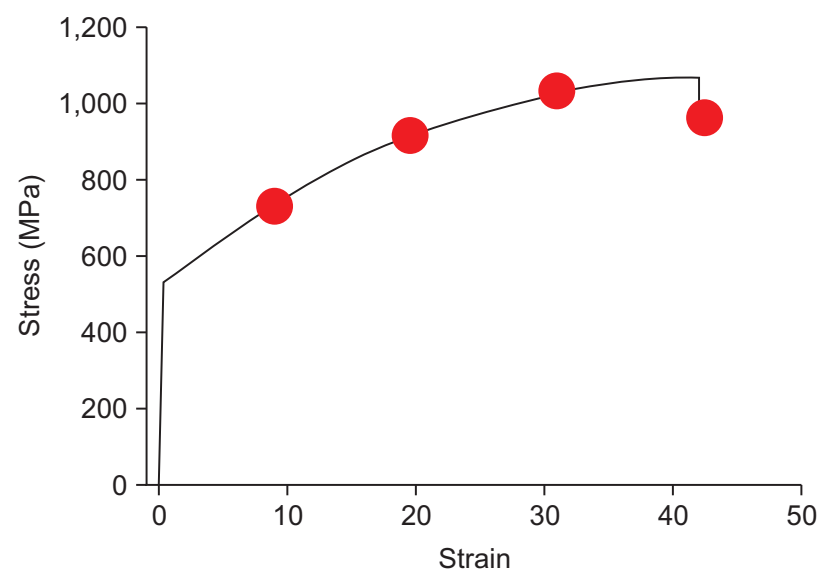

Fig. 1. Stress-strain curve of twinning-induced plasticity steel.

and Schmid factors for each twin system result in the same trend under uniaxial stress. However, the interaction energy calculation can be applied for multi-axial loads, whereas Schmid factors are valid under uniaxial tension in a single crystal.

\section{MATERIALS AND METHODS}

The TWIP steels used in this study contained $0.6 \mathrm{wt} \%$ of C, $1.6 \mathrm{wt} \%$ of $\mathrm{Al}$, and $18 \mathrm{wt} \%$ of $\mathrm{Mn}$. The average grain size was $3.81 \mu \mathrm{m}$. The high-manganese TWIP steel specimens were austenitic at room temperature. Tensile test specimens $25 \mathrm{~mm}$ in gauge length and $6.25 \mathrm{~mm}$ in diameter were machined from a bulk sample. Specimens were deformed into four tensile-strained states: $10 \%$ strained, $20 \%$ strained, $30 \%$ strained, and fractured. Fig. 1 shows the stress-strain graphs of the specimens (red dots in the stress-strain curve indicate the specimen state). For TEM measurements, thin foils were collected from the center part of the deformed specimens within the gauge length and prepared in a twin-jet electrolytic polishing apparatus using a solution containing $10 \%$ perchloric acid and $90 \%$ ethanol. The microstructures of the steel were observed by TEM 3000F (JEOL, Japan; operated at $300 \mathrm{kV}$ ). The tensile direction was marked in the specimen from the beginning of specimen preparation to track the tensile direction in an individual grain. Notably, the tensile direction in the specimen is the most critical parameter in the analysis. To determine the relation between the tensile direction and the twin system in each grain by TEM, the specimen was tilted to zone $<110>$ and diffraction patterns (DPs) were obtained. The accurate tensile direction within each grain was obtained using rotation angles during TEM observations and through corresponding coordinate transformation matrices.

The internal energy of the $k^{\text {th }}$ variant, $U^{k}$, in Table 1 is defined as 


$$
U^{k}=\sigma_{c}: \varepsilon_{c}^{k}
$$

where $\sigma_{c}$ is the stress tensor with considering reorientation of the austenite matrix by twinning and $\varepsilon_{c}^{k}$ is the strain tensor due to twinning in the austenite crystal coordinate system. Strain tensor $\varepsilon^{k}$ is given by

$$
\varepsilon_{c}^{k}=\frac{\gamma}{2}\left(n^{k} \otimes s^{k}\right)
$$

where $n^{k}, s^{k}$, and $\gamma$ are the twinning-plane normal, the twinning direction, and the magnitude of shear $(1 / \sqrt{2}$ in face-centered cubic), respectively.

Fig. 2A shows a DP from a grain of the $10 \%$ strained specimen and the coordinate-transformed tensile direction. The calculated internal energy of each 12-twin variant for the tensile direction is displayed in Fig. 2B, where the 12th variant of each red graph indicates the experimentally observed variant. All of the values are positive because the reverse twinning direction was considered in each variant. Also, the numbers on the red bar shown in the graph correspond to twin systems showing experimental results.

\section{A}
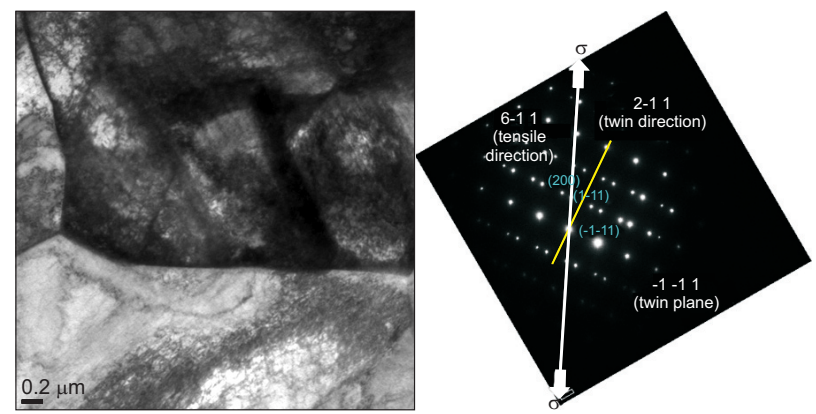

\section{B}

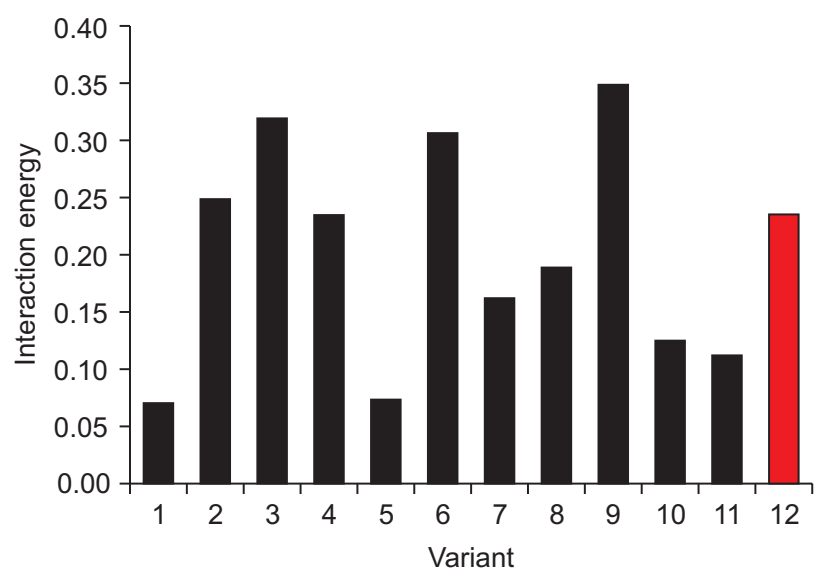

Fig. 2. (A) Diffraction pattern of the $10 \%$ strained sample; the tensile direction, twin direction, and twin plane are indicated. (B) Graph representing the calculation results of internal energy with 12 twin variants.

\section{RESULTS AND DISCUSSION}

We have determined the relation between the generated twin systems and the applied tensile directions in a total of 80 grains from the four types of strained specimens. To clearly identify twin images, we collected both bright-field and dark-field TEM images. The index of the tensile direction obtained through the DP was determined by transforming the coordinate of the initial tensile direction by applying rotating angles of the TEM holder. One of the DPs from the $10 \%$ strained specimen is shown in Fig. 2A, in which the twin direction and twin plane as well as the projected tensile direction are indicated. The interaction energies with the order of Table 1 are shown in Fig. 2B, and the experimentally determined variant is marked with the red color.

The results for all 80 cases are summarized in Fig. 3 by categorization into one of three cases: (a) exact agreement between the experiments and theoretical calculations; that is, the experimentally determined twin system has the lowest

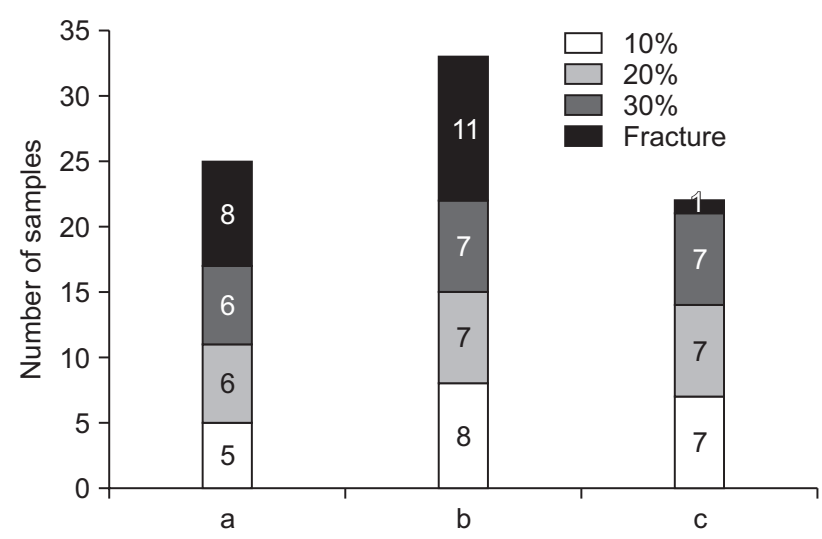

Fig. 3. Experiment results categorized into three cases: (a) exact agreement, (b) fair agreement, and (c) disagreement.

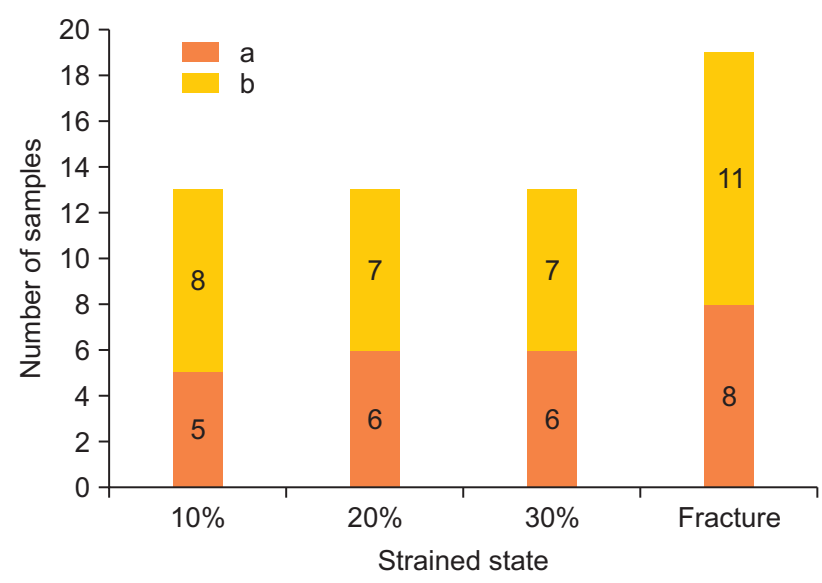

Fig. 4. The number of samples with exact agreement and fair agreement grouped in each strained state. 
A

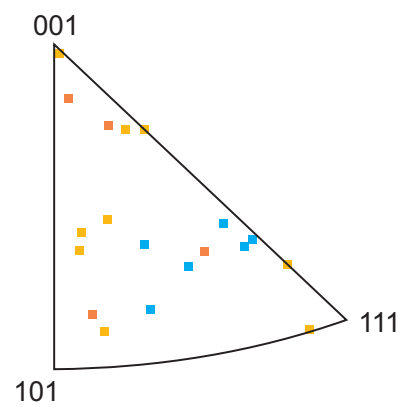

C

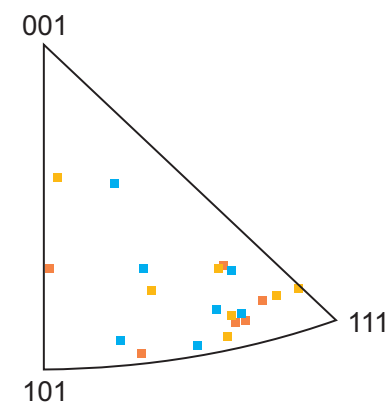

B

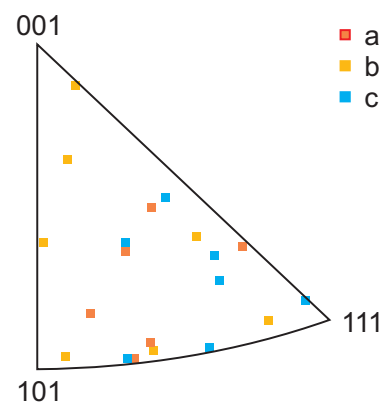

D

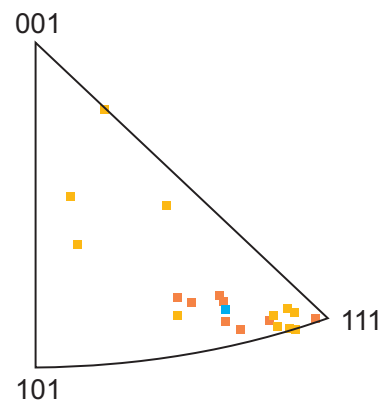

Fig. 5. Inverse pole figure map: (A) $10 \%$ strained sample, (B) $20 \%$ strained sample, (C) $30 \%$ strained sample, and (D) fractured sample. Here a, b, and c represent exact, fair and no agreements, respectively.

energy; (b) the difference between the lowest internal energy and the energy of the experimentally observed twin system is within a standard deviation (1-sigma) of the calculated energies; and (c) other cases.

The numbers of grains with exact (a) or fair (b) agreement in the four strained samples are replotted in Fig. 4. Except for the case of fractured specimens, no distinctive characteristics are observed among the strained specimens. Overall, approximately $70 \%$ of the 80 observed grains show close consistency between the calculations and the experiments. The agreements between the experimental observations and theory in the 80 grains are indicated in the inverse pole figure map (Fig. 5). For the $10 \%$ and $20 \%$ strained specimens, the three types ( $a, b$, and c) of grains are uniformly distributed. In the 30\% strained and fractured specimens, however, grains with good agreements are concentrated near the [001]-[111] direction. This observation indicates that grains likely rotated toward the $[001]-[111]$ line when the external tension was applied. Fig. 6 shows the overall structure of the specimen with no strain (pristine) and the specimen with 30\% strain, as determined using electron backscatter diffraction (EBSD); these results clearly reveal that the number of grains with the [111] direction increased when the specimens were pulled

in the rolling direction, in contrast to the cases of $10 \%$ and $20 \%$ strained specimens. Notably, the generation of twins in materials or the rotation of the crystals has been reported to sometimes be suppressed depending on grain size (Godet et al., 2006; Hong et al., 2009; Scheriau \& Pippan, 2008; Ueji et al., 2008; Yang et al., 2006). Although the mean grain size of the specimens used in the present experiment was 3.814 $\mu \mathrm{m}$, such effects could potentially occur because the sizes of individual grains were very different. Additionally, unexpected errors may exist because of interactions with surrounding grains (Barbier et al., 2009; Han et al., 2004; Karaman et al., 2000; Pérez-Prado \& Doncel, 2006; Vercammen et al., 2004).

\section{CONCLUSIONS}

In the present study, twin systems generated under various tensile stress strengths and directions were characterized using TEM and the results were compared with calculated interacting energies in austenite-structured, polycrystalline TWIP steels. Experiments were conducted for 80 different grains from four strain cases of $10 \%, 20 \%, 30 \%$, and up to fracture to reflect real application conditions. Among the 80 observed grains, $72 \%$ (58 grains out of 80 grains) exhibited perfect or fair agreement between experimental results and calculation results. Grains with good agreements between calculation results and experimental results were concentrated near the [111] direction in the 30\% strained and fractured specimens. These results are consistent with our observation that the tension axis approached the [001]-[111] direction when the material was subjected to tension. EBSD results also showed that an increase in crystal direction toward the [111] direction under the progression of tension, consistent with the aforementioned observations.

In the present study, we demonstrated the feasibility of prediction deformation through calculation of interaction energies for the mechanical twins and the tendency of deformed grains moving toward specific directions.

\section{CONFLICT OF INTEREST}

No potential conflict of interest relevant to this article was reported.

\section{ACKNOWLEDGMENTS}

This work was supported by the National Research Foundation of Korea (NRF) grant funded by the Ministry of Science, ICT \& Future Planning (MSIP) (No. NRF2015R1A5A1037627). 

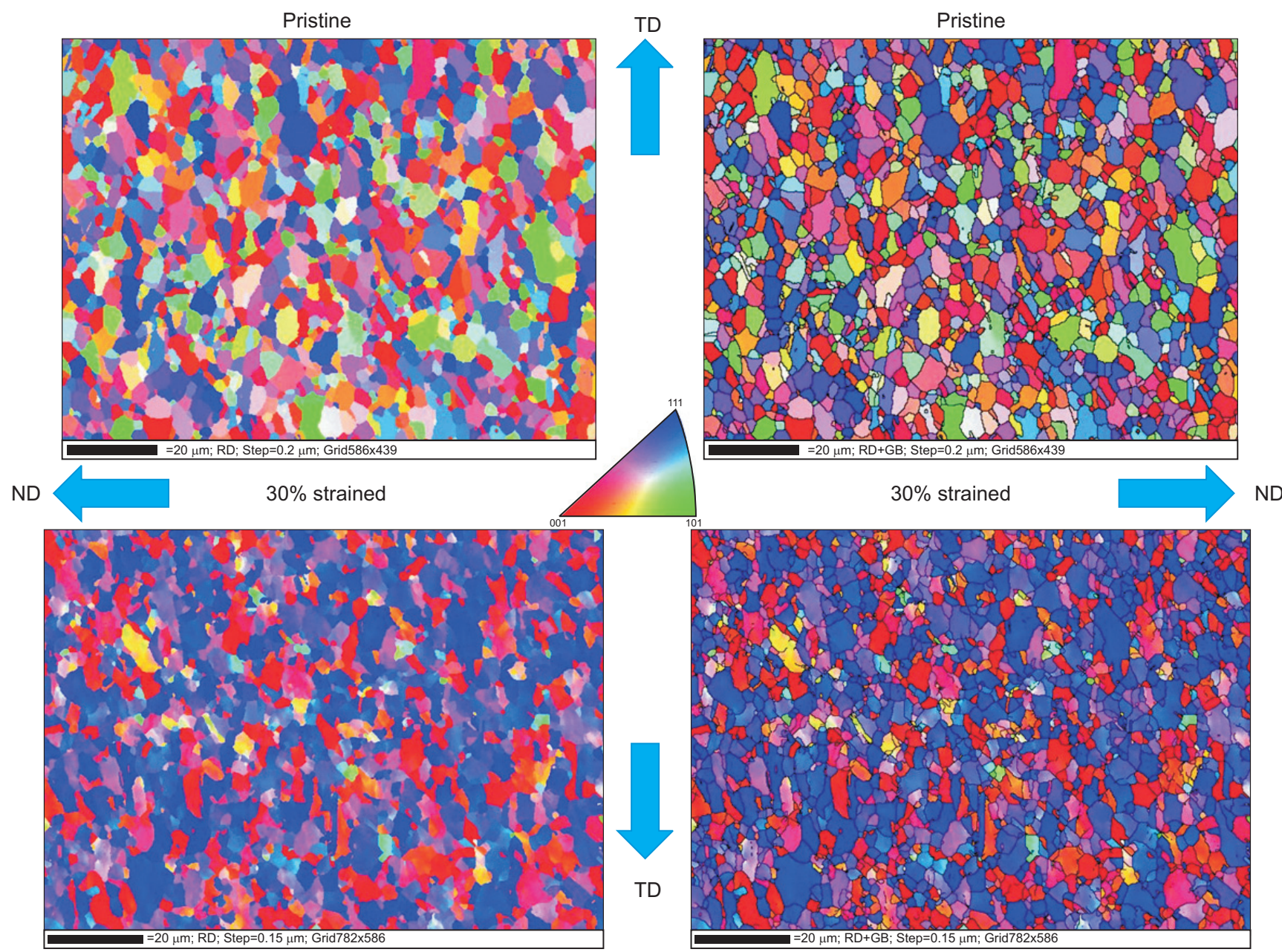

Fig. 6. Electron backscattered diffraction map of a pristine sample and a 30\% strained sample (scale bar: $20 \mu \mathrm{m}$ ). TD, transverse direction; ND, normal direction.

\section{REFERENCES}

Ahn T H, Lee S B, Park K T, Oh K H, and Han H N (2014) Strain-induced $\varepsilon$-martensite transformation during nanoindentation of high-nitrogen steel. Mat. Sci. Eng. A 598, 56-61.

Allain S, Chateau J P, and Bouaziz O (2004) A physical model of the twinning-induced plasticity effect in a high manganese austenitic steel. Mat. Sci. Eng. A 387, 143-147.

Barbier D, Gey N, Allain S, Bozzolo N, and Humbert M (2009) Analysis of the tensile behavior of a TWIP steel based on the texture and microstructure evolutions. Mat. Sci. Eng. A 500, 196-206.

Frommeyer G, Brüx U, and Neumann P (2003) Supra-ductile and highstrength Manganese-TRIP/TWIP steels for high energy absorption purposes. ISIJ Int. 43, 438-446.

Godet S, Jiang L, Luo A A, and Jonas J J (2006) Use of Schmid factors to select extension twin variants in extruded magnesium alloy tubes. Scripta Mater. 55, 1055-1058.

Han J H, Kim D I, Jee K K, and Oh K H (2004) Evolution of crystallographic orientations in an aluminum single crystal during tensile deformation. Mat. Sci. Eng. A 387, 60-63.
Hong C S, Tao N R, Lu K, and Huang X (2009) Grain orientation dependence of deformation twinning in pure $\mathrm{Cu}$ subjected to dynamic plastic deformation. Scripta Mater. 61, 289-292.

Hua D, Zheng-You T, Wei L I, Mei W, and Dan S (2006) Microstructures and mechanical properties of Fe-Mn-(Al, Si) TRIP/TWIP steels. J. Iron Steel Res. Int. 13, 66-70.

Hull D and Bacon D J (2001) Introduction to Dislocation (ButterworthHeinemann, London).

Idrissi H, Ryelandt L, Veron M, Schryvers D, and Jacques P J (2009) Is there a relationship between the stacking fault character and the activated mode of plasticity of Fe-Mn-based austenitic steels? Scripta Mater. 60, 941-944.

Karaman I, Sehitoglu H, Gall K, Chumlyakov Y I, and Maier H J (2000) Deformation of single crystal Hadfield steel by twinning and slip. Acta Mater. 48, 1345-1359.

Lee S H, Kang J Y, Han H N, Oh K H, Lee H C, Suh D W, and Kim S J (2005) Variant selection in mechanically-induced martensitic transformation of metastable austenitic steel. ISIJ Int. 45, 1217-1219. 
Pérez-Prado M T and Doncel G G (2006) Lattice rotation during severe local shear in a fully hardened $\mathrm{Al}-4 \% \mathrm{Cu}-0.1 \%$ Fe single crystal alloy. Scripta Mater. 54, 915-919.

Scheriau S and Pippan R (2008) Influence of grain size on orientation changes during plastic deformation. Mat. Sci. Eng. A 493, 48-52.

Ueji R, Tsuchida N, Terada D, Tsuji N, Tanaka Y, Takemura A, and Kunishige $\mathrm{K}$ (2008) Tensile properties and twinning behavior of high manganese austenitic steel with fine-grained structure. Scripta Mater. 59, 963-966.
Vercammen S, Blanpain B, De Cooman B C, and Wollants P (2004) Cold rolling behaviour of an austenitic Fe-30Mn-3Al-3Si TWIP-steel: the importance of deformation twinning. Acta Mater. 52, 2005-2012.

Yang P, Xie Q, Meng L, Ding H, and Tang Z (2006) Dependence of deformation twinning on grain orientation in a high manganese steel. Scripta Mater. 55, 629-631. 